\title{
Imagens de celulares e narrativas de estudantes e professoras de artes de Macapá/AP
}

\author{
Cell phone images and narratives of students and art teachers from \\ Macapá/AP(Amapá State)
}

Clicia Tatiana A. Coelho

Erinaldo Alves do Nascimento ${ }^{i}$

\begin{abstract}
Resumo
Este artigo reflete sobre as imagens armazenadas nos telefones celulares de um grupo de estudantes do Ensino Fundamental e suas reverberações no contexto educativo, compreendendo a ação de armazenar tais imagens como mote difusor de processos de subjetivações. Utiliza a análise de discurso para considerar as regularidades e inconstâncias existentes nos modos que estudantes e professoras de Artes veem e são vistos pelas imagens. Discute sobre as formas que os colaboradores da pesquisa relacionam-se com as imagens, principalmente, no contexto escolar a partir de alguns princípios da Educação da Cultura Visual.

Palavras-chave: Imagem, Processo de subjetivação, Ensino de Artes Visuais, Cultura Visual.
\end{abstract}

\section{Abstract}

This article reflects upon the images stored on the mobile phones of a group of elementary school students and their reverberations in the educational context, including the action of storing such images as a spreading motto of subjectivity processes. This paper uses discourse analysis to address the regularities and inconsistencies that exist within the ways students and Art teachers see and are seen through images. This work discusses the ways research participants relate to images especially through some principles of Visual Culture Education.

Keywords: Image, Process of subjectivation, Visual Arts Teaching, Visual Culture.

\section{Introdução}

Iniciada em 2011 e concluída 2013, no Programa de Mestrado em Artes Visuais (PPGAVUFPB/UFPE), esta pesquisa foi desenvolvida por Clicia Coelho, na condição de mestranda, sob a orientação do prof. Dr. Erinaldo Alves do Nascimento, da UFPB (COELHO, 2013). Surgiu de uma experiência de docência em Artes e da necessidade de compreender algumas situações vivenciadas por professores e estudantes, no cotidiano, relativas à presença do telefone celular na escola e, principalmente, discutir as imagens armazenadas pelos estudantes em tais dispositivos.

O objetivo da pesquisa foi conhecer como eram as narrativas visuais (fixas e móveis) e orais que um grupo de estudantes do $9^{\circ}$ ano, de uma escola pública, em Macapá/AP-BR, armazenava e transportava diariamente, nos seus telefones celulares e como as professoras de Arte desta escola relacionavam-se com tais imagens. 


\section{Imagens armazenadas e processos de subjetivação}

Começamos essa discussão estabelecendo uma ampla aproximação com o pensamento adiante:

a ausência de um olhar crítico e sem sentido de responsabilidade, pode deixar as pessoas vulneráveis à manipulação da crescente e inesgotável diversidade de imagens - de arte, publicidade, ficção e informação - que, de múltiplas maneiras nos interpelam, invadem e sitiam nosso cotidiano. Imagens têm vida cultural e exercem poder psicológico e social sobre os indivíduos (MARTINS, 2008, p. 34).

A ideia de problematizar sobre a farta veiculação imagética ocorrida por meio do telefone celular usados por jovens estudantes e as suas possibilidades educativas, despertaram o interesse em analisar as implicações e os deslocamentos entre a ideia metafórica de saber se os sujeitos armazenam as imagens ou se as imagens armazenam os sujeitos. Uma pergunta desponta em decorrência desta metáfora: as imagens armazenadas pelos jovens estudantes, também, tem o potencial de "armazená-los"?

A pertinência desta pergunta parte da ideia que a imagem constitui-se, de maneira imaginada ou materializada, por uma dinâmica cultural mediadora de poderes psíquicos e sociais sobre os sujeitos. O uso metafórico do termo "armazenar" está associado com a noção de sujeito e de subjetivação.

Conforme a etimologia, sujeito vem do latim subjectum, que significa "posto debaixo"; "o que se encontra na base". Tomando-se a noção de sujeito e a associando com a de subjetividade, ou seja, com os modos pelos quais nos tornamos sujeitos, é possível pensar em um sujeito que está "debaixo" de convenções construídas culturalmente e, a um só tempo, na base da formulação das resistências e da busca por liberdade. Neste aspecto, os sujeitos são produtores de saberes e, simultaneamente, subjetivados e objetivados pelos saberes que produzem (NASCIMENTO, 2005).

Pode-se afirmar que os jovens estudantes armazenam as imagens nos seus telefones celulares como uma forma de resistência e de liberdade em relação ao discurso pedagógico vigente e, simultaneamente, são armazenados pelas imagens que selecionam. As imagens armazenam e fazem projeções, modelando suas subjetividades. Eis, então, a razão da metáfora: os jovens estudantes armazenam e são "armazenados" pelas imagens dos seus telefones celulares.

O termo "armazenar", usado metaforicamente, alude às escolhas e introjeções processadas a partir das imagens que os jovens podem fazer para serem e se 
autodefinirem como sujeitos, como adolescentes, como estudantes e como pertencentes à cultura juvenil.

Para Hernández (2010), a perspectiva de uma educação transformadora precisa conceber a imagens como produtoras de valores culturais e que sobrepujam metáforas surgidas da necessidade social de construir significados que expliquem a própria vida. $O$ autor defende um ensino da Arte que valorize as possibilidades interpretativas contidas em tais simbologias em diferentes culturas para, quem sabe, reproduzi-las ou criar novas maneiras de ver e pensar sobre elas.

Ainda de acordo com Hernández (2010), interpretar significa dar ênfase a diferentes fenômenos visuais, problematizando sobre suas origens, forças e os poderes que as fazem existir. Parte-se da compreensão que a interpretação é parte fundamental de um currículo educacional preocupado com a construção psicossocial do estudante. É muito importante que os estudantes possam interpretar as imagens, contestando-as e suspeitando de interpretações naturalizadas como "verdades" incontestáveis, presentes nas relações de poder e de saber na sociedade contemporânea.

Conhecer os posicionamentos dos colaboradores da pesquisa - um grupo formado por quatro professoras de Artes e outro por oito estudantes - sobre as imagens contidas nos celulares dos estudantes, possibilitou-nos tecer relações interpretativas, para além do simples cruzamentos de dados coletados. Provocou-nos a enveredarmos por uma análise, enfatizando como as imagens e suas interpretações são demarcadas por relações de saber e de poder, podendo-se recorrer ao passado para ajudar a desconfiar e rever o presente no qual se incutem culturalmente (NASCIMENTO, 2011).

Um dos questionamentos feitos às professoras colaboradoras durante a pesquisa de campo foi sobre a importância que atribuíam às imagens no processo de ensino e de aprendizagem. Dentre as várias declarações, a fala ${ }^{1}$ da professora Teresa, chamou a nossa atenção. Para ela, a imagem desenvolve um papel de grande importância pelos seguintes motivos:

[...] Quando você fala da imagem, você leva o aluno a imaginar a cor, imaginar a forma, ele só imagina... Quando você mostra a imagem, eles entendem melhor. $E$ eu observo isso quando o trabalho é sobre os artistas e suas obras de arte, sobre pintura e arquitetura. Você percebe que o aluno grava melhor, passa a conhecer melhor. Você traz o que tá longe, aproxima pra vida deles. A imagem faz aproximar o aluno da obra de arte. E o faz

\footnotetext{
Os diálogos presentes no texto foram destacados com formatação diferenciada e transcritos integralmente. Ressaltamos que os mesmos são devidamente autorizados e preservam o anonimato dos colaboradores da pesquisa.
} 
perceber que a arte não tá simplesmente nos museus. Não é tão distante deles. As TIC possibilitam essa aproximação. Mesmo que seja só a imagem. Eu acho que essas imagens que eles têm nos celulares... Pra mim, não existe essa coisa de que uma imagem vale mais que a outra. Essa coisa de que a obra de arte é melhor que as coisas do telefone celular. Não é questão de valer mais. Eu não vejo assim. Até porque a imagem que ele tem agora tá chamando atenção por algum motivo. Então, tem um certo valor pra ele. Pode não ter assim... Digamos... Um valor comercial. Mas tem algum valor. Porque despertou, chamou atenção. Então, assim... Eu não vejo como se fosse assim... Porque é obra de arte, porque tá no museu, porque é de um artista renomado, que tem mais valor que as outras que ele carrega no celular. Inclusive, eu uso as imagens do dia-a-dia nas aulas. As imagens das revistas, da mídia... Eu uso também.

Com bastante desenvoltura e eloquência, Teresa expôs como concebe e pratica pedagogicamente a sua relação com as imagens para além do ambiente escolar. Ela estabelece conexões entre o currículo estruturado e suas possibilidades ampliadas para a vida cotidiana do aluno, compreendendo as TIC como ferramentas capazes de colaborar efetivamente para o processo de ensinar e de aprender.

A professora demonstra empenho em aprender a lidar com as transformações contemporâneas para melhor servir e atender aos interesses mais urgentes dos educandos. Mas, reconhece que se trata de uma tarefa árdua, requerendo bastante atenção. Outro ponto relevante do posicionamento dessa colaboradora foi a relação que ela estabelece entre as obras de artes e as imagens cotidianas, ou entre as 'Belas Artes' e as imagens da cultura popular. A professora compreende que ambas são importantes para o processo educacional.

Segundo as perspectivas da Educação da Cultura Visual (ECV), toda imagem produzida culturalmente tem potencial narrativo para promover embates e discussões críticas a cerca da vida. Por isso, não permite categorização hierárquica entre uma ou outra produção imagética. Ao contrário, problematiza e defende a educação pelo viés reflexivo, por meio das visualidades que fazem parte efetivamente do dia-a-dia do alunado, numa ação dialógica que inclua o sujeito e suas reais possibilidades de argumentação. Rejeita um ensino aprisionado em cânones artísticos, que não valoriza e nem abre espaço para as múltiplas formas de representação.

Uma imagem é aquilo que imita ou representa pessoas ou coisas, ou seja, é a representação mental ou física de qualquer forma (MICHAELIS, 1998). Kerry Freedman (2005, p. 126) afirma que "imagens são uma forma poderosa de representação. Boa parte desse poder está em seu caráter interpretativo". 
Freedman também considera que a concepção de Arte é um processo representacional historicamente construído. Por isso, a importância da tomada de novas veredas interpretativas que atendam aos interesses da sociedade contemporânea. Defende a valorização das informações e dos conhecimentos que os alunos vão adquirindo fora da escola.

Cotidianamente, crianças e adolescentes são expostos a imagens propagadas pela cultura de massa. No entanto, "os alunos não veem essas imagens criticamente, a menos que sejam ensinados a fazê-los" (FREEDMAN, 2005, p. 130). Ao tentar compreender como os estudantes se relacionam com a cultura de massa, possibilitará o desenvolvimento de políticas educacionais condizentes com os interesses da contemporaneidade.

A partir dos posicionamentos da equipe docente sobre as imagens que alunos e alunas armazenam em seus telefones celulares, foi possível constatar que, unanimemente, todas afirmam que já se depararam com o fascínio que o dispositivo e suas possibilidades de uso provocam nos estudantes. O contraditório foi perceber que as professoras, raramente, conectam-se a este fascínio na elaboração e execução dos projetos pedagógicos.

O depoimento da professora Maria, colaboradora da pesquisa, explicita com veemência como ocorre esse deslumbramento.

Pesquisadores: Como você vê a relação que os estudantes têm com seus telefones celulares?

Maria: Olha, é como se fosse ou fizesse parte deles. É um amor incondicional que eles têm pelo celular. Eles não conseguem viver sem o celular. Tudo gira em função do celular pra eles. (Risos) Seja pela música que gostam de ouvir, seja pelas ligações, pelas fotos, vídeos ou mensagens. Tudo isso chama a atenção dos alunos. Por isso que falo que é um amor incondicional. Todos têm. É difícil mesmo encontrar um deles sem celular e olha que a escola é pública e tem muita gente carente. Mesmo assim, eles têm telefones e olha que é um mais moderno que o outro.

As entrevistas individuais e as conversas focalizadas ${ }^{2}$ realizadas com a equipe docente da escola ACP, realizadas no mês de março de 2012, geraram outras constatações acerca do

2 A entrevista individual, também conhecida como entrevista em profundidade, é uma conversa entre entrevistador e o entrevistado, uma interação díade, ou seja, em dupla, que visa estabelecer mais confiança e segurança ao entrevistado. A discussão em grupo focal pode ser definida como um método de coleta de dados 
foco do estudo, reforçando o caráter contraditório do "fascínio" e de sua apropriação nos projetos pedagógicos, como os expostos a seguir:

- as quatro professoras possuíam telefone celular e, também, utilizavam esse dispositivo para armazenar arquivos de seus interesses como músicas, imagens fixas e móveis;

- conheciam ou faziam ideia dos arquivos armazenados nos celulares dos alunos;

- reconheciam a importância do uso das TIC na educação e da constante qualificação para saber administrar as mudanças no contexto contemporâneo. No entanto, reforçaram que precisavam de apoio técnico pedagógico mais eficiente para desenvolver tais atividades;

- relataram situações consideradas corriqueiras como os alunos ouvirem música, acessarem a Internet, fazerem ou acessarem imagens fixas e móveis durante a aula;

- relataram que a escola ACP não possui regras bem definidas a respeito do uso do celular na sala da aula;

- duas professoras afirmaram que nunca pensaram em desenvolver atividades escolares utilizando o celular como ferramenta e duas já realizaram atividades escolares utilizando os recursos do telefone celular para fotografar e filmar;

- nunca desenvolveram atividade utilizando os arquivos imagéticos pessoais dos estudantes armazenados nos seus celulares;

- reconheciam a importância do cotidiano para o planejamento das aulas;

- três professoras afirmaram trabalhar com imagens das Belas Artes e, também, com imagens da cultura de massa em suas aulas e uma delas afirmou trabalhar apenas com imagens de obras de arte;

- demonstraram dificuldades para explicar como concebem e praticam propostas pedagógicas, como a abordagem triangular e a educação da cultura visual;

- afirmaram que seus cursos de Licenciatura em Educação Artística apresentaram déficit nas suas formações e que sempre procuram fazer cursos de qualificação profissional;

- afirmaram que seguiam o plano curricular estruturado pela secretaria de educação, mas fazem modificações para atender as necessidades da realidade escolar.

qualitativos que possibilita a análise de declarações e relatos sobre experiências e eventos, especialmente, quando se pretende discutir tópicos especiais sugeridos pelo pesquisador de forma interativa com o contexto e quando os tópicos da conversa são considerados delicados (COELHO, 2003). 
Diante destas verificações inferimos que a equipe docente reconhece a importância de se adotar novas possibilidades educacionais no campo do ensino das Artes Visuais e da Arte/Educação. Intuímos que se estas constatações fossem generalizadas, outros docentes, também, se debateriam com essas problemáticas.

Consideramos plausível depreender, a partir dos dados encontrados nesta pesquisa, juntamente com a nossa experiência como docente, que existem muitos entraves que dificultam essas mudanças. São limitações de ordens pessoais e, principalmente, sistêmicas, instauradas historicamente no percurso do Ensino de Artes no Brasil. Pois, apesar de terem ocorrido importantes transformações nesse campo, ainda se propagam concepções e práticas que ainda não atendem ou tem grande dificuldade para atender aos interesses da educação atual.

Somente a partir da década de 1980, intensificaram-se as pesquisas acerca da Arte/Educação com abordagens contemporâneas para tratar das questões do ensino e da aprendizagem, principalmente, nas instituições de ensino formal, em defesa do desenvolvimento cognitivo e cultural do estudante. Essas pesquisas abrangeram mudanças de discursos modernistas a fim de instaurar outros condizentes com as transformações da sociedade. As mudanças perpassaram por tendências da arte como linguagem, como cultura e, mais recentemente como cultura visual.

As mudanças mais significativas foram instituídas na legislação brasileira principalmente com a Lei no 9.394, de 20 de dezembro de 1996, que estabeleceu as Diretrizes e Bases da Educação Nacional (BRASIL, 1996); os Parâmetros Curriculares Nacionais para o ensino de arte, oficializados em 1997 (BRASIL, 1997 e 2010); a Lei no 10.172, de 9 de janeiro de 2001, que aprovou o Plano Nacional de Educação e deu outras providências, que também passaram por transformações em 2007 (BRASIL, 2001 e 2007).

É importante ressaltarmos que qualquer tentativa de delimitação acerca das tendências educacionais, concepções e práticas do ensino das Artes Visuais não podem ser entendidas como completas e definitivas. A esse respeito, é possível afirmar que:

o sistema educacional é afetado deliberadamente pela 'tradição do novo' em oposição à 'tradição do antigo'. Rupturas e descontinuidades ocorrem a cada reforma, a cada modismo, a cada mudança de governo. A continuidade mais evidente é a da iminência de rupturas e descontinuidades. [...] Mutações discursivas e educacionais ocorrem, principalmente, em decorrência de alterações no equilíbrio das relações entre poder e saber. Os nomes da arte na educação e os respectivos programas educacionais estabelecem-se porque denunciam, com competência 
intelectual e respaldo político e econômico, limitações na maneira de ver, dizer e fazer anteriormente aceitas. A pertinência epistemológica e discursiva coadunam-se com a conveniência política e econômica (NASCIMENTO, 2005, p. 238, grifos do autor).

A busca constante por metodologias e abordagens que atendam aos interesses imediatos da sociedade contemporânea precisa estar em sintonia com a intenção do professor crítico e reflexivo, atentando constantemente para o cotidiano do alunado. Essa busca não consiste necessariamente em abandonar ou descartar 'táticas metodológicas' anteriormente instituídas, ao contrário, a articulação e combinação entre procedimentos podem levar a resultados significativos, se forem bem planejados e bem aplicados. $O$ fator determinante para a escolha metodológica precisa se coadunar com a necessidade de cada ação.

De acordo com as perspectivas da Educação da cultura visual, o interesse em conhecer, considerar e problematizar as imagens que os estudantes escolhem e armazenam em seus celulares devem decorrer justamente pela crescente demanda de acesso a essas mídias por parte desse público. Isso ocorre porque, diariamente, professores presenciam o deslumbramento que essas mídias exercem sobre os estudantes, necessitando que seja, efetivamente, dada a devida importância no planejamento escolar.

Hernández (2007) compreende o professor como mediador, aquele que identifica, indaga, critica e cria a partir da cultura visual. Aquele que, metaforicamente, é um catador de possibilidades e aprendiz atento às necessidades mais urgentes de seus alunos. "Deixam, então, de ser transmissores de informações a uma audiência passiva, para se transformarem em 'autores', junto com os alunos, em um processo de reelaboração de suas próprias experiências" (HERNÁNDEZ, 2007, p. 89).

O trecho da entrevista abaixo, realizada com a professora Sônia, colaboradora da pesquisa, expõe a existência de uma dinâmica de acesso aos arquivos dos alunos e formas de intercâmbio cotidiano. Mesmo que essa interação ocorra de maneira desinteressada no sentido de não fazer parte do planejamento da aula, ainda assim configuram-se em importantes agências de mediação.

Pesquisadores: Você faz ideia do tipo de arquivos e conteúdo que os estudantes armazenam em seus telefones?

Sônia: Sim, com certeza. Eles arquivam muita imagem, muita música e vídeos. É... Eu acho que são esses arquivos que eles mais têm.

Pesquisadores: E como você tem acesso aos arquivos dos celulares deles? 
Sônia: Às vezes passando... Caminhando pela sala a gente vê. Eu nunca tive a curiosidade pra ver. Melhor dizendo, eu já pedi pra ver, sim, mas, não foi agora. Já faz um tempinho (Risos). Pedi para a aluna passar um vídeo pra mim porque a minha filha queria. Eu a vi mexendo no celular e eu aproveitei para pedir e ela passou. Era um arquivo baixado da Internet.

É nesta interação cotidiana "desinteressada" com os estudantes e rica de troca de experiências, que as professoras baseiam-se e relatam sobre os arquivos que eles armazenam em seus celulares. A figura 01, construída a partir do cruzamento dos dados coletados, mostra em ordem decrescente os arquivos de imagens armazenados nos celulares, mais acessados pelos estudantes.

Figura 01. Tipos de arquivos presentes nos celulares dos estudantes

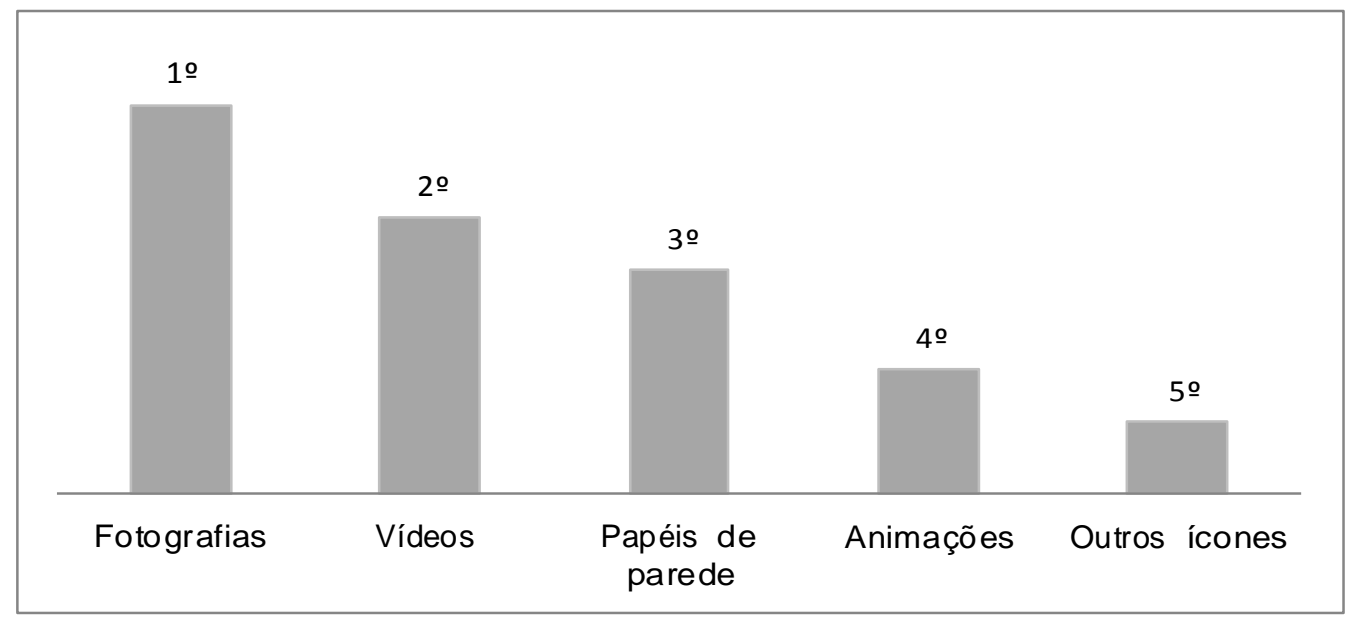

Fonte: Coelho (2013, p. 108)

As fotografias ocuparam o primeiro lugar nos arquivos de imagens armazenados nos telefones celulares dos estudantes. São os mais presentes e acessados. De acordo com as professoras, isso se deve ao fato de quase todos os telefones celulares possuem câmeras fotográficas.

Entre tais arquivos, existe a predominância de fotos de autorretratos, de amigos e de familiares. São fotos feitas para registrar a dinâmica do dia-a-dia.

Em segundo lugar, está a preferência por vídeos. Estes, da mesma forma que as fotografias, são muito comuns. Isso pode decorrer pelo fato de ser um recurso tecnológico comum nos celulares. Dependendo do modelo do telefone celular, possuem mais ou menos qualidades de áudio e vídeo. 
Dentre os vídeos acessados pelos estudantes estão, em maior parte, os baixados da Internet, que são trocados via Bluetooth (sistema de troca de dados entre dispositivos como telefones celulares, notebooks, impressoras, câmeras digitais e consoles de videogames digitais através de uma frequência de rádio de curto alcance) e os que são produzidos pessoalmente, usando a câmera filmadora do telefone celular.

Os temas mais comuns são os associados às imagens consideradas inapropriadas para menores de idade por possuírem cunho sexual e/ou pornográfico, o humor, a violência e as cenas da vida cotidiana dos próprios estudantes. O depoimento da professora Maria explicita com detalhes a preferência de alguns temas entre os estudantes.

Maria: Eu percebo que os alunos têm muita pornografia armazenada no telefone (Risos). Nesse caso, são mais os meninos. Eles têm muitas imagens, muitas músicas do tipo deles, imagens do tipo deles, que eles pegam na rua. Eles brincam na sala de brigar e gravam. Já os vi gravando a fala e filmando os professores. Eles fazem imagens das aulas dos professores até pra usar isso contra o professor. Isso eu já vi acontecer aqui na escola. Gravam aquilo que o professor fala sem o professor saber de nada. Adoram filmar as brigas entre eles... Passam um para o outro e pegam as imagens dos outros da escola toda. Gostam dessas coisas de violência. Eles baixam da Internet imagens de filme pornô. Quando a gente os vê em grupinhos e rindo... Geralmente é isso que eles estão vendo. Pornografia. (Risos) E olha que já vi crianças de $5^{a}$ série. A gente vê isso em todas as séries... Como eu dou aula para as $5^{a}$, eu vejo mais entre eles.

Ao analisarmos os relatos das professoras, dos estudantes e os arquivos imagéticos coletados na pesquisa de campo, constamos um grande interesse por "conteúdos considerados inapropriados para menores de idade", principalmente, no que se refere à imagem com teor sexual e/ou pornográfico.

A figura 02 foi elaborada a partir de cenas de um vídeo armazenado no celular de um aluno. Trata-se de um making of, documentário de bastidores de um ensaio fotográfico de uma revista direcionada ao público adulto, cuja protagonista é popularmente conhecida na mídia brasileira como Mulher Melancia.

Figura 02- Cenas do vídeo: making of da Mulher Melancia, arquivo coletado na pesquisa de campo, 2012. 


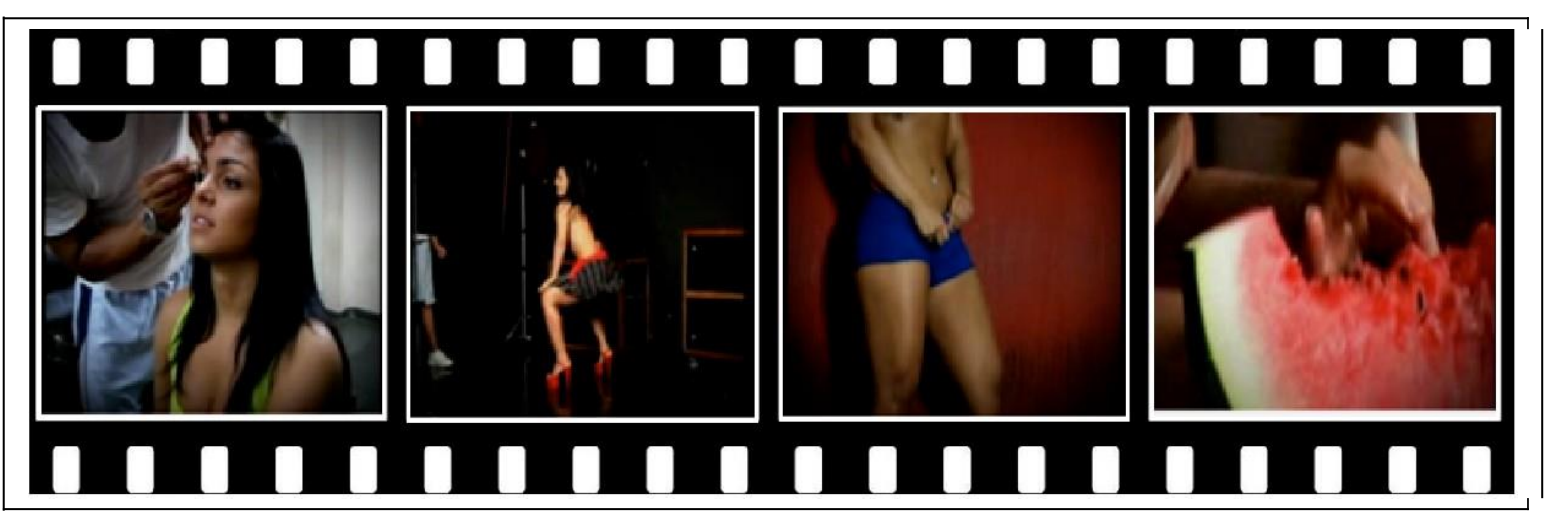

Fonte: Coelho (2013, p. 109)

$\mathrm{Na}$ discussão focalizada realizada no mês de março de 2012, com os estudantes, questionamos a respeito da preferência por armazenarem arquivos de conteúdo considerados proibido para a faixa etária deles. No início demonstraram constrangimento para discorrer sobre o tema, no entanto, bastou um começar a falar para a conversa crescer, conforme pode ser observado no diálogo abaixo.

Pesquisadores: Porque a timidez para falar sobre esses arquivos? Vocês acham que é um problema?

Carlos: É um problema, sim, professora. (Risos).

Pan: Na minha concepção é porque a gente tem vergonha dos pais, das outras pessoas. Tipo assim... Muitos adolescentes não conversam com os pais. Então, já que eles não têm isso em casa, eles vêm pra escola e acessam essas coisas. E fazem tudo aquilo que eles não podem fazer em casa, eles fazem aqui na escola. Entendeu?! Então eu acho que parte disso, também, é culpa dos familiares. Na minha concepção, pode ser uma coisa errada sim, mais numa outra não. Porque no ponto de vista deles pode não ser. Entendeu? Então, acho assim, que... Se você for perguntar para cada um deles, eles consideram isso uma coisa certa, porque são homens. Tipo assim... Eles têm a concepção de mulher daquela forma, dessas aí... Assim, meio peladas. (risos). Então assim, tem que ter a conversa dos pais com os adolescentes, senão a gente vai descobrir de uma forma bem diferente e pode ser a errada. Entendeu?

O posicionamento de Pan aponta uma situação conflitante entre o que se ensina, relacionado à educação pensada e executada pelos pais e instituições formais, e, o que os adolescentes consideram importante aprender e conhecer. Configurando contextos divergentes, um de caráter impositivo por parte de quem educa e outro subversivo, por parte de quem é educado, pois a vida para estes, pulsa em outra direção.

Para Marc Prensky (2001), as crianças nascidas em qualquer nova cultura interagem facilmente com o desafio das novas linguagens e reagem com resistência as que para 
eles pareçam "velhas". Suas atitudes, consideradas como rebeldes, muitas vezes são guiadas pela vontade de se manifestar contra aquilo que julgam antiquados.

O terceiro quesito analisado foi o papel de parede, que são as imagens fixas que os alunos geralmente usam como plano de fundo no visor do telefone celular. Neste caso, geralmente são imagens de arte digital, na maioria, coletadas da internet e trocada entre eles utilizando o celular. As fotografias de autoimagem também aparecem como papel de parede. As imagens (figura 03), coletadas com os estudantes, materializam nossas constatações.

Figura 03 - Imagens de papel de parede coletados na pesquisa de campo, 2012.

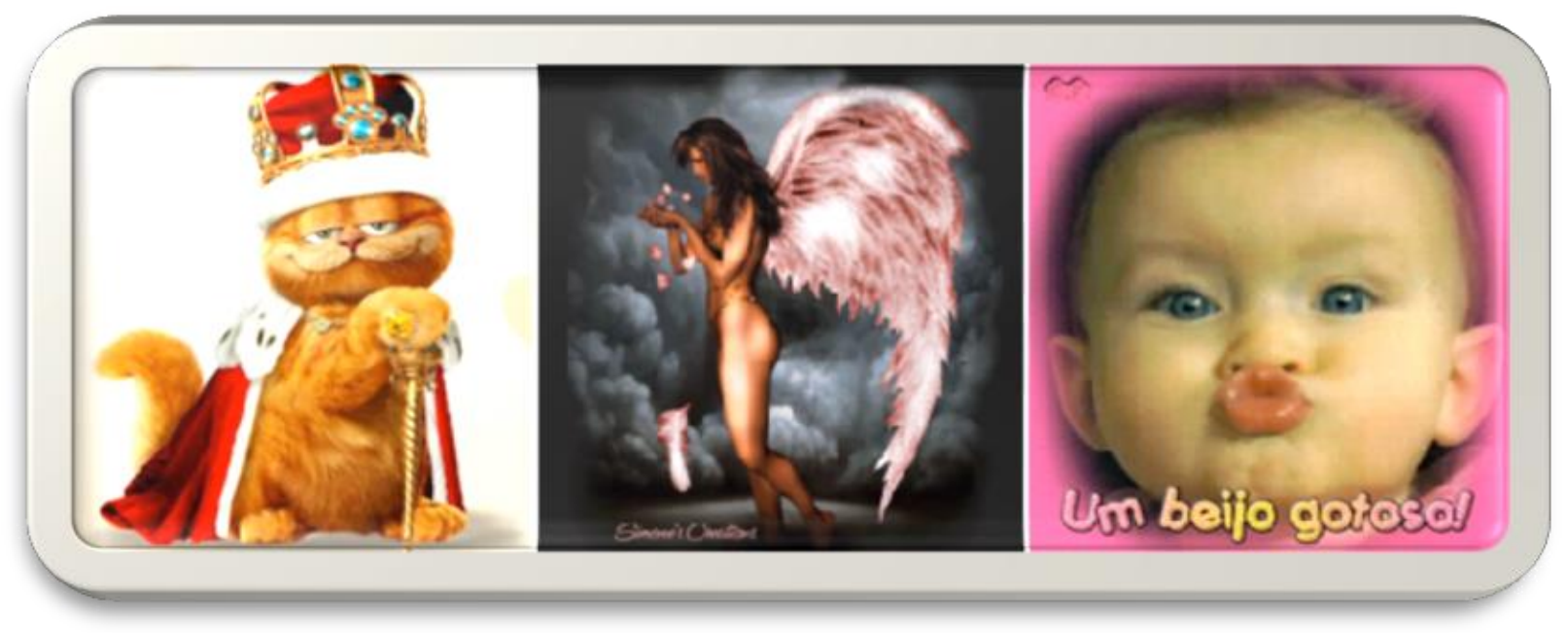

Fonte: Coelho (2013, p. 111)

As imagens de animação que compuseram o quarto quesito do gráfico, da figura 01 são desenhos, charges, cartuns e caricaturas, que muitas vezes apresentam algum efeito de movimento e de caráter humorístico. Já o quinto e último quesito, chamado de outros ícones vinculam-se aos símbolos, ícones e caracteres imagéticos, também, conhecidos como emoticons, smileys e winks amplamente difundidos em dispositivos e interfaces computacionais. Podem ser considerados tipos de animação criados com a intenção de dinamizar e ilustrar a comunicação digital e virtual.

Chamamos atenção para a forma que a professora Teresa narra sua experiência cotidiana com os alunos e o uso que eles fazem do telefone celular na escola. No depoimento abaixo, ela expõe detalhadamente essa relação.

Eles têm imagens de plano de fundo do celular, me passam vídeos engraçados, de piada. Eles têm imagens pornográficas também. Sei que eles armazenam esses arquivos e trocam com os colegas. Têm muitas fotografias que eles fazem na escola, dos colegas, deles mesmos. Eles gostam das coisas que estão na mídia. Alguns 
pedem pra fazer fotos minhas quando estou dando aula. Eles perguntam: professora, posso tirar uma foto sua? Então eles batem fotos quando eu estou sentada, fazendo a chamada. Um dia desses um aluno me mostrou um aborto pelo celular. Na imagem, parecia um bebezinho, mas depois era uma coisa horrorosa. Eu disse: Ah menino, não me mostra essas coisas que eu não gosto de ver! (risos) Era uma coisa muito feia. Eles adoram essas coisas de terror, atrocidades e acidentes. Eu nem gosto de ver. Um dia me mostraram um vídeo da internet onde vários meninos pulavam de uma rampa n'água e tinha um deles que pulava e batia a cabeça numa pedra e partia a cabeça. Ai, que horror! Eles adoram carregar isso no telefone. Têm alguns que já me conhecem, que já foram meus alunos desde a $5^{a}$ série e querem me assustar com essas coisas. Eles se divertem com a minha cara (risos).

Nesta narrativa, a professora Teresa, demonstra entrosamento e intimidade na relação dialógica com os estudantes. Expressa perplexidade diante dos conteúdos que os estudantes armazenam nos celulares e ressalta que os interesses deles estão voltados para as imagens da cultura de massa. Dessa forma, é possível mais uma vez, constatar que as imagens das 'Belas Artes', não fazem parte do interesse dos estudantes, no que se refere a guardá-las e carregá-las no telefone celular.

A exposição dos quesitos de imagens e a forma como as professoras de Artes pensam, foram adotadas, nesse momento, para dar visibilidade ao fato de que elas têm conhecimento, interagem e até reconhecem o potencial desses arquivos como possibilidades pedagógicas. Porém, não as absorvem como recursos para suas práticas, como alternativa para estabelecer uma aproximação entre o "gosto refinado" e preferências pessoais pelo uso das imagens das belas artes, como manutenção de valores historicamente instaurados, frente ao bombardeio de imagens produzidas pela indústria midiática.

Nesse sentido, percebemos a existência de conflitos entre culturas. De um lado a cultura escolar com seus discursos consolidados e, de outro, a cultura midiática, que diariamente é posta a disposição dos usuários por meio de variados dispositivos.

Os pesquisadores Tourinho e Martins (2011, p. 56) alertam sobre esta situação afirmando que:

condições e circunstâncias apontam para a necessidade de formar professores de arte preparados não apenas para analisar imagens, artefatos artísticos e tecnológicos, mas especialmente, para ajudar os alunos a compreender e desenvolver uma atitude crítica em relação à indústria da imagem e do entretenimento. 
A necessidade de compreender e atender aos interesses emergentes da sociedade precisa fazer parte das metas da educação na contemporaneidade. A adoção de procedimentos metodológicos pautados na dinâmica do cotidiano merece fazer parte das escolhas dos educadores, pois, as "novas" exigências sociais apontam para a importância de estimular ou desenvolver competências para que o aluno possa aprender a lidar com tais demandas.

Fazer conexões entre variadas formas de construções culturais amplia as possibilidades de contribuir de forma crítica para a formação dos educandos, especialmente, o público infanto-juvenil, com faixa etária em processo acelerado de desenvolvimento e heterogeneidade. $O$ ensino das artes visuais, voltado para os jovens, precisa envolver suas peculiaridades como sujeitos sociais ativos, que historicamente produzem "vozes rebeldes" de protesto contra as coisas postas e ou impostas. Eis, em suma, algumas características que consideramos de extrema importância para a formação intelectual e psicossocial do sujeito.

Ao analisar as imagens dos celulares dos estudantes, juntamente com as entrevistas e os registros de diário de campo, percebemos a existência de dois eixos distintos que merecem ser discorridos. Um deles delineia uma regularidade, no sentido de apontar para uma certa homogeneidade e persistência nos modos em que as narrativas imagéticas - vídeos, fotografias, papéis de parede, animação e outros ícones se apresentam, e também, nas formas em que os colaboradores da pesquisa narram sobre elas. O outro eixo delineia uma inconstância, revelando uma instabilidade na maneira em que esses mesmos quesitos sobrepuseram-se.

No referente à regularidade das narrativas sobre as imagens dos celulares, constatamos a persistência em armazenar arquivos advindos da cultura de massa, principalmente, aqueles que fazem parte da mídia - do conjunto dos meios de comunicação social atual, como: imprensa radiofônica, televisiva, publicação na Internet, videograma, satélite de telecomunicação, etc., ou seja, todo e qualquer suporte e difusão de informação, destinado a um grande público. São imagens que versam sobre situações cotidianas, vinculadas às vivências, preferencialmente, da cultura juvenil.

A concepção de cultura de massa empregada aqui está baseada nas prerrogativas postuladas por Néstor García Canclini (1998), em sua obra Culturas Híbridas: estratégias para entrar e sair da modernidade. Para este autor, o conceito de cultura de massa está imbricado de aspectos multiculturais e desdobra-se em uma "nova" demanda que ele chamou de culturas híbridas. 
Depreende-se, a partir do exposto, que a cultura de massa é formada a partir da interrelação de outras formas culturais, como cultura religiosa, popular, culta, religiosa, nacional, etc. Entende-se, neste caso, que um mesmo produto ou artefato, pode ser concebido, lido ou interpretado de diversas maneiras, dependendo da formação socioeconômica e histórica do consumidor.

García Canclini, não compreende a cultura de massas de forma isolada, pois defende que:

o culto, o popular e o massivo não estão onde estamos habituados a encontrá-los. É necessário demolir essa divisão de três pavimentos, essa concepção em camadas do mundo da cultura e averiguar se sua hibridação pode ser lida com as ferramentas das disciplinas que os estudam separadamente: a história da arte e a literatura se ocupam do 'culto'; o folclore e a antropologia, consagrados ao popular; os trabalhos sobre comunicação, especializados na cultura massiva. Precisamos de ciências nômades, capazes de circular pelas escadas que ligam esses pavimentos (CANCLINI, 1998, p. 19).

Consideramos propício relacionar a ideia de cultura híbrida às representações culturais juvenis ${ }^{3}$, nas quais se insere o publico investigado. As ações que movem os adolescentes são heterogêneas, transeuntes e fortemente impregnadas pela mídia, que se alimenta da ambivalência entre a cultura popular e a culta.

Outra regularidade percebida corresponde à predominância de arquivos imagéticos, na maioria de origem midiática, relacionados às questões identitárias, que reforçam e demarcam condições de gênero, sexualidade, família, ciclo de amizade, padrões de beleza, moda, humor, estilo musical e violência na escola.

Nesse ponto, a vida cotidiana desses jovens, com suas especificidades e características culturais peculiares, atua como principal mote para a escolha e a manutenção de tais arquivos.

É interessante notar que é a partir dessa regularidade e persistência, que as inconstâncias são percebidas, principalmente pelo fato de haver diferença entre o que as "meninas" e os "meninos" armazenam em seus celulares.

As imagens (vídeos, fotografia, papel de parede...) comuns entre os arquivos dos colaboradores do sexo masculino são, em sua maioria, relacionados com a sexualidade,

3 Tema discutido em Coelho (2013) e Coelho e Nascimento (2013). 
ou seja, exploram mulheres nuas ou seminuas em poses sensuais, coisas que não aparecem nos arquivos das alunas colaboradoras da pesquisa. Também, estão presentes entre a preferência só dos homens, as imagens sobre time de futebol, carros e motos.

Entre os arquivos mais comuns das mulheres e que quase não apareceram entre a preferência dos homens, estão os relacionados à família, amizade, moda, mensagens de otimismo e de relacionamento amoroso. As figuras 04 e 05 caracterizam as imagens que demonstram as preferências predominantes entre os arquivos dos meninos e das meninas respectivamente.

Figura 04 - Imagens recorrentes nos celulares dos alunos colaboradores da pesquisa

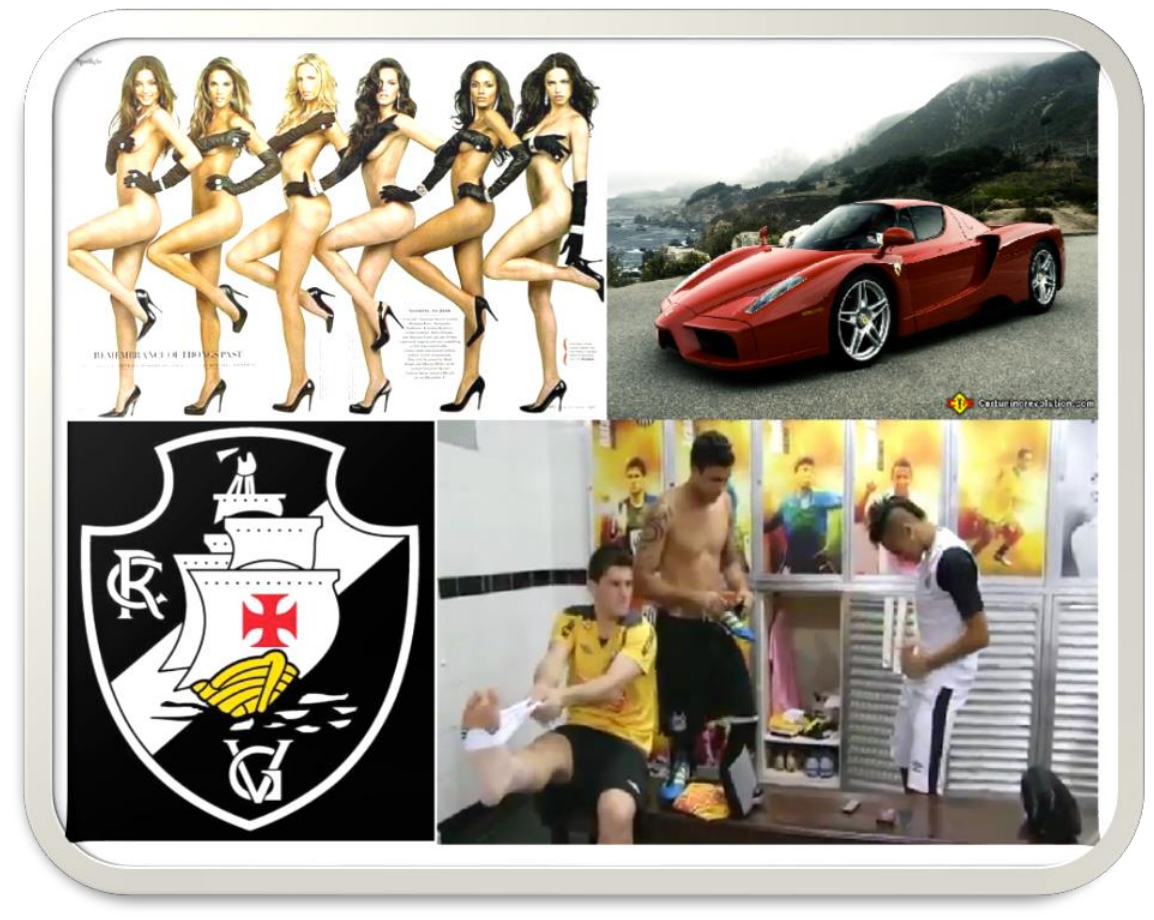

Fonte: Arquivo dos autores

Figura 05 - Imagens recorrentes nos celulares das alunas colaboradoras da pesquisa 


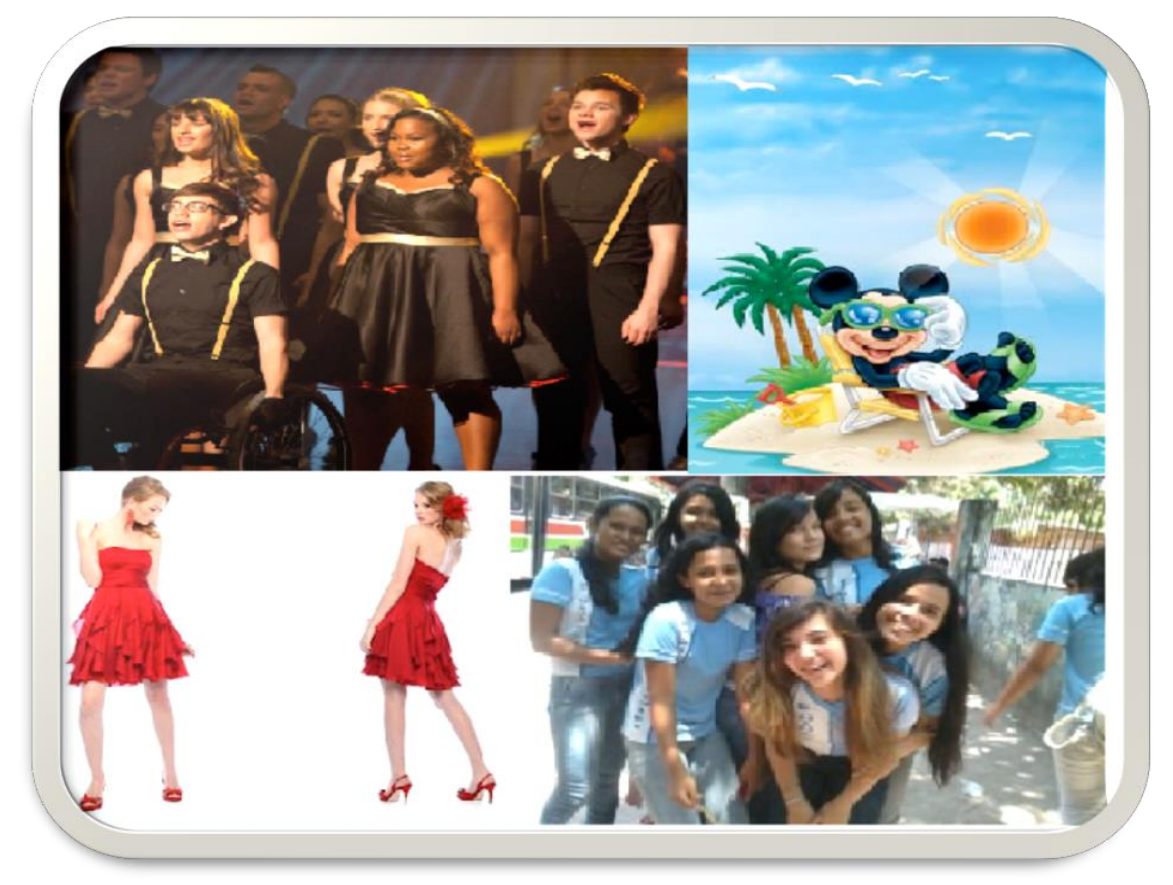

Fonte: Arquivo dos autores

\section{Considerações gerais e conclusivas}

Ao trilhar os caminhos em busca das pistas que nos levassem ao objetivo de conhecer e analisar como eram as narrativas imagéticas (fixas e móveis) e orais que um grupo de estudantes do 90 ano, de uma escola pública, armazenava e transportava, diariamente, em seus telefones celulares, bem como as narrativas proferidas pelas professoras de Arte desta mesma escola sobre tais imagens, constatamos a preferência dos estudantes por imagens da mídia e não por imagens de Arte - Belas Artes - e que essa preferência se dá, muito mais, por falta de envolvimento significativo para suas vidas.

Isso leva a depreender que ir para a sala de aula estudar conteúdos descontextualizados, que não fazem sentido para a vida dos jovens, não atendendo às suas necessidades, não Ihes parecem atraentes e por isso, são descartados ou rejeitados. Força-os a uma permanência na escola para suprir obrigações momentâneas como, por exemplo, alcançar média para passar de ano.

Reforçamos que a intenção desta discussão não é desmerecer a função das Belas Artes no processo educativo da disciplina de Artes. Ao contrário, reiteramos a importância de considerar todos os tipos de imagens presentes na cultura visual de maneira planejada e condizente com a ação pedagógica destinada a um público específico e heterogêneo.

Reconhecemos que as Belas Artes, com todo seu potencial e riqueza visual, fornece a área de ensino incontestável contribuição. No entanto, sua abordagem curricular merece 
especial atenção para que não seja apenas reprodutora de padrões anteriormente estruturados e não ressignificados.

As imagens armazenadas nos telefones celulares dos estudantes sofrem e os fazem sofrer constantes processos de subjetivação. Ao mesmo tempo em que eles as escolhem e as armazenam em seus dispositivos móveis, estão sendo armazenados por elas.

Um ensino das Artes Visuais comprometido com as mudanças educacionais contemporâneas precisa voltar-se para essas urgências emergentes e torná-las foco de constantes discussões.

\section{Referências}

BRASIL. Câmara. Senado. Lei no 9.394, de 20 de dezembro de 1996. Estabelece as diretrizes e bases da educação nacional. Diário Oficial da República Federativa do Brasil, Brasília, DF, 23 dez. 1996. Seção 1, p. 27.839.

Ministério da Educação. Secretaria de Educação Fundamental. Parâmetros Curriculares Nacionais: arte. Brasília, DF: MEC, SEF, 1997.

Lei no 10.172, de 9 de janeiro de 2001. Aprova o Plano Nacional de Educação e dá outras providências. PNE verso e reverso: Plano Nacional de Educação. Rio de Janeiro: Folha Dirigida, 2001.

Ministério da Educação. Plano de Desenvolvimento da Educação. Brasília, DF, 2007. Disponível em: <http://www.mec.gov.br>. Acesso em jun. 2012.

- Ministério da Educação. Diretrizes Curriculares Nacionais para o Ensino Fundamental de 9 (nove) anos. Resolução CNE/CEB 7/2010. Diário Oficial da União, Brasília, 15 de dezembro de 2010, Seção 1, p. 34. Disponível em http://portal.mec.gov.br/>. Acesso em ago. 2013.

CANCLINI, N. G. Culturas Híbridas: estratégias para entrar e sair da modernidade. Tradução: Heloísa P. Cintrão e Ana Regina Lessa. 2a Ed. São Paulo: EDUSP, 1998.

COELHO, C. T. A. Imagens de celulares e práticas culturais juvenis no cotidiano escolar. 2013. 167f. Dissertação (Mestrado em Artes Visuais) - Universidade Federal da Paraíba, Universidade Federal de Pernambuco, João Pessoa, 2013. 
FREEDMAN, K. Currículo dentro e fora da escola: representações da arte na cultura visual. In: BARBOSA, Ana Mae (Org.). Arte/educação contemporânea: consonâncias internacionais. São Paulo: Cortez, 2005.

HERNÁNDEZ, F. Catadores da Cultura Visual: proposta para uma nova narrativa educacional. Porto Alegre: Mediação, 2007.

- Como pode a educação da cultura visual contribuir com a educação das artes. In: RODRIGUES, E. B. T; ASSIS, H. L. (Orgs.). Educação das artes visuais na perspectiva da cultura visual: conceituações, problematizações e experiências. SEDUC, GO, 2010, p. 59-86.

MARTINS, R. Das belas artes à cultura visual: enfoques e deslocamentos. In: MARTINS R. (Org.) Visualidade e educação. Goiânia: FUNAPE, 2008, p. 25-35.

MICHAELIS, Moderno dicionário da língua portuguesa. São Paulo: Companhia Melhoramentos, 1998, p. 2260.

NASCIMENTO, E. A. Mudanças nos nomes da arte na educação: qual infância? Que ensino? Quem é o bom sujeito docente? São Paulo, 2005, Tese (Doutorado em Artes), Universidade de São Paulo.

. Singularidades da educação da cultura visual nos deslocamentos das imagens e das interpretações. In. MARTINS, R.; TOURINHO, I. (Org.). Educação da cultura visual: conceitos e contextos. Santa Maria: Ed. da UFSM, 2011, p. 209-226.

PRENSKY, M. Digital Natives, Digital Immigrants. MCB University Press, 2001. Disponível em: <http://www.marcprensky.com/writing/prensky\%20\%20digital\%20natives,\%20digital\%20immigrants\%20-\%20part1.pdf>. Acesso em mar. 2012.

TOURINHO, I; MARTINS, R. Circunstâncias e ingerências da cultura visual. In: MARTINS, R.; TOURINHO, I. (Org.). Educação da cultura visual: conceitos e contextos. Santa Maria: Ed. da UFSM, 2011, p.51-69. 
icliciacoelho@gmail.com

Grupo de Pesquisa em Ensino de Artes Visuais

Universidade Federal da Paraíba

i erinaldo_alves@hotmail.com

Grupo de Pesquisa em Ensino de Artes Visuais

Universidade Federal da Paraíba

Recebido em: 23/09/2013

Aprovado em: 15/10/2013 